\title{
FRASEOLOGÍA Y LINGÜÍSTICA COGNITIVA. ESTUDIO INTERDISCIPLINAR DE LA FRASEOLOGIZACIÓN DE LA LOCUCIÓN SOMÁTICA DE BOCA EN BOCA
}

\author{
Alicia Merino GonZÁlez \\ Universidad de Valencia \\ aliciamerinogonzalez@gmail.com
}

Recibido: 03/06/2015

Aceptado: 02/09/2015

\begin{abstract}
Resumen
En este artículo se analiza la fraseologización de la locución somática (LS) de boca en boca. Para ello, se abordará el objeto de estudio mediante la imbricación de la fraseología y la cognición, pues la lingüística cognitiva puede arrojar luz al estudio de la aparición, fijación e idiomaticidad del fraseologismo mediante los mecanismos figurativos. El proceso de fraseologización requiere la documentación de la locución en corpus diacrónicos y sincrónicos para trazar el proceso evolutivo de la unidad fraseológica (UF). La LS que se estudiará se encuentra en las obras lexicográficas actuales, no obstante, solo mediante el estudio diacrónico se logrará averiguar qué variantes o variaciones han dado lugar a esta combinación fija de palabras que conocemos hoy en día.

PALABRAS CLAVE: Fraseología, fraseologización, lingüística cognitiva, mecanismos figurativos.
\end{abstract}

\begin{abstract}
In this article is analyzed the phraseologization of the somatic locution (SL) de boca en boca. To do this, the object of study is discussed by the imbrication between the phraseology and the cognicion, then, the cognitive linguistic can give off light on the study of the appearance, fixation and idiomatic of the phraseologies though the figurative mechanisms. The phraseologication's process requires the documentation of the locution in diachronic and synchronous corpus in order to draw the evolutionary process of phraseological unit (PU). The SL that is studied is in the actual lexic, however, only with the diachronic study is found out which variants and variations grow this fixed combination of know today.

KEYWORDS: Phraseology, phraseologization, cognitive linguistic, figurative mechanism.
\end{abstract}

\section{Introducción}

En el presente trabajo se presentará un estudio diacrónico de una unidad fraseológica somática (UFS). En concreto, se trata de la locución somática de boca en boca, locución que presenta como núcleo el somatismo boca. En primer lugar, se debe destacar la hegemonía de los estudios sincrónicos de los fraseologismos y la escasez de investigaciones desde la perspectiva diacrónica. Así pues, se pretende contribuir a la profundización y desarrollo de dicha perspectiva histórica con la finalidad de mostrar la importancia de esta para comprender las unidades fraseológicas actuales. Asimismo, presentamos la perspectiva diacrónica y sincrónica como complementarias y constituyentes de un continuo; por lo que se aboga por la realización de estudios que abarquen tanto la perspectiva diacrónica como la sincrónica.

En segundo lugar, se debe destacar la interdisciplinaridad que caracteriza a la fraseología como disciplina, hecho que permite llevar a cabo estudios en los cuales se imbrica con otra 
disciplina. El estudio llevado a cabo por Ruiz (2001) muestra la posibilidad de complementar la fraseología y lingüística cognitiva desde una perspectiva sincrónica. Este trabajo es clave para esta investigación, pues se pretende analizar desde las perspectivas diacrónica y sincrónica la aparición, fijación y consolidación de la LS; para ello, el estudio se sustentará en la interdisciplinaridad que presentan tanto la fraseología como la lingüística cognitiva. De este modo, el estudio fraseológico y cognitivo nos permite dar cuenta de la aparición, creación y fijación de la combinación fija de palabras a través de los mecanismos figurativos, en concreto, de la metáfora y la metonimia (Lakoff y Johnson, 1980; Cuenca y Hilferty, 2013).

En tercer lugar, al tratarse de una locución somática se cree oportuna la imbricación de la fraseología y la lingüística cognitiva, ya que los hechos físicos del cuerpo humano pueden posibilitar la motivación o creación de significados figurados. Asimismo, las características, propiedades y funciones de la boca pueden influir en la aparición del fraseologismo de boca en boca, así como de sus variantes y variaciones.

De las apreciaciones presentadas se desprende el principal objetivo de este trabajo que es analizar desde las perspectivas diacrónica y sincrónica la creación, evolución y consolidación del fraseologismo somático de boca en boca. Para ello, se imbrica la fraseología y la lingüística cognitiva, ya que esta última puede arrojar luz al estudio de la aparición y fijación de la unidad fraseológica que nos ocupa, así como de las variantes y variaciones que se articulan en torno a esta.

\section{Estado de la cuestión}

La delimitación del objeto de estudio como locución somática y la restricción de los mecanismos figurativos a la metáfora y la metonimia presentan como ineludibles los estudios cognitivos para dar cuenta de la intersección que se produce entre la fraseología y la lingüística cognitiva. Así pues, en los siguientes apartados se presenta el origen y recorrido de la fraseología como disciplina, una aproximación al cognitivismo, los estudios diacrónicos que se han realizado y las contribuciones en el terreno somático. Además, se tendrá en cuenta los diferentes postulados respecto a la metáfora y la metonimia, así como los estudios que plantean la imbricación entre fraseología y cognición.

\subsection{La fraseología como disciplina}

El origen de la fraseología como disciplina se halla en los lingüistas soviéticos, pues estos fueron los que consideraron dicha disciplina como autónoma al resto de ramas de la lingüística. No obstante, esta concepción ha evolucionado hasta contemplarse como una rama interdisciplinar, tal y como sustenta Ruiz (1998). El objeto de estudio de esta disciplina ha pasado por diferentes estadios y denominaciones, pues a pesar de consolidarse el término unidad fraseológica o fraseologismo (Zuluaga, 1980), se propusieron otros que no se llegaron a consolidar: expresión pluriverbal (Casares, 1992 [1950]) y expresión fija (Zuluaga, 1980).

La aportación llevada a cabo por Casares (1992[1950]) consiste en distinguir locuciones y fórmulas pluriverbales, caracterizándose las primeras por ser una combinación estable de dos o más términos que funciona como un elemento oracional y presenta sentido. Respecto a las fórmulas pluriverbales, se debe tener en cuenta que este autor las presenta como autónomas y sin función oracional. La clasificación elaborada por Casares es continuada por 
Zuluaga (1980), quien no contempla las colocaciones y presenta como objeto de estudio las combinaciones de al menos dos palabras e incluso de aquellas que conforman un enunciado.

Corpas (1997) combina el criterio de enunciado (acto de habla) con el de fijación que generan el primer nivel de clasificación donde se distinguen UF en tres esferas. A partir del concepto de enunciado presenta dos grupos de UF que son las que no constituyen un enunciado completo y las que sí lo conforman. En el primer grupo se halla los fraseologismos que no constituyen actos de habla ni enunciado (son los equivalentes a un sintagma) y este grupo, a su vez se subdivide en dos esferas que son la I (formada por UF que se fijan en la norma, es decir, las colocaciones) y la esfera II (constituida por UF pertenecientes al sistema, es decir, las locuciones). Por otro lado, en el segundo grupo están las UF que pertenecen al acervo sociocultural, por lo que la esfera III está formada por unidades del habla: enunciados fraseológicos, es decir, unidades fijadas en el habla constituyentes de actos de habla independientes. En el segundo nivel de la clasificación se presentan las divisiones de las tres esferas y en este se especifica qué tipos de colocaciones, locuciones y enunciados fraseológicos hay.

De la contribución de Ruiz se debe destacar el trabajo llevado a cabo en torno a las locuciones adverbiales, pues esta autora clasifica estas locuciones con esquema Prep $C$ en tres grupos: a) Los sintagmas prepositivos propiamente dichos; b) las unidades fraseológicas verbales en las que aparece un verbo y un complemento precedido por una preposición; y c) fraseologismos con formas diferentes a los sintagmas prepositivos, como por ejemplo, cara a cara. Además de esta clasificación, presenta las diferentes funciones que dichas locuciones adverbiales pueden desempeñar: modificadores del verbo, modificadores del predicado sin presentar relación sintáctico-semántica con él y modificadores oracionales (1997: 33).

Para finalizar con el recorrido histórico de la formación de la fraseología como disciplina, así como la delimitación y clasificación de sus objetos de estudio, se debe tener en cuenta la aportación de García-Page (2008). Este autor refleja la diversidad de locuciones y añade las oracionales a las clasificaciones realizadas por las autoras mencionadas en párrafos anteriores. Asimismo, da cuenta en profundidad de las características de los fraseologismos en los diferentes niveles y muestra la heterogeneidad del universo fraseológico.

\subsection{La perspectiva diacrónica}

Los estudios sincrónicos predominan sobre los diacrónicos, hecho que se puede constatar al observar el elevado número de contribuciones desde la perspectiva sincrónica y el reducido número de estudios diacrónicos. A este aspecto hacen referencias autoras como Pérez-Salazar (2007) y Echenique (2011), quienes abordan los fraseologismos desde la perspectiva diacrónica e inciden en su importancia para el conocimiento tanto de la fraseologización como de la comprensión de la unidad fraseológica actual. Se deben tener en cuenta estudios fraseológicos tales como los de Martí (2004) y Pérez-Salazar (2007), ya que en el primero se lleva a cabo la investigación de fraseologismos en el siglo XVIII, y en el segundo se presenta la evolución de las UF a lo largo de los siglos. De dichas aportaciones, debemos destacar la de Pérez-Salazar (2007), pues guarda cierta similitud con el estudio que se llevará a cabo en esta contribución. En "Unidades fraseológicas y diacronía. Sobre las fórmulas negativas de ninguna manera y en absoluto" observamos la documentación de los fraseologismos y variantes en los corpus de referencia, por lo que se traza la fraseologización y productividad de dichos fraseologismos. 
Por último, destacar la afirmación de Pérez-Salazar (2007), pues prevé un aumento progresivo de estudios históricos. Asimismo, en el presente artículo se contribuirá a la aproximación de las UF desde la perspectiva diacrónica a través de la investigación de la fraseologización de la locución de boca en boca.

\subsection{Aproximación a la lingüística cognitiva}

La lingüística cognitiva se caracteriza por ser un movimiento lingüístico que en palabras de Ibarretxe-Antuñano y Valenzuela "concibe el lenguaje como un fenómeno integrado dentro de las capacidades cognitivas humanas" (2012: 13). De hecho, uno de los rasgos definitorios es la corporeización (embodiment), la cual describe Johnson (1987) como la motivación más o menos directa del lenguaje mediante la experiencia corpórea, física, social y cultural.

El germen de la lingüística cognitiva se halla en la obra de Chomsky (1957) debido a que esta supone una revolución para la concepción del lenguaje y las ciencias cognitivas. No obstante, no fue hasta el 1980, cuando con la obra Metaphors we live by (Lakoff y Johnson, 1980) se marcase el inicio de la lingüística cognitiva y el declive del generativismo. Estos autores mediante su obra presentaron la metáfora y la metonimia como mecanismos cognitivos utilizados en la vida cotidiana, y por lo tanto, no exclusivos de la literatura. Cabe destacar la contribución de Fillmore (1985) al basarse en la psicología cognitiva para formular las bases de la semántica de marcos. Esta semántica se caracteriza por ofrecer una perspectiva novedosa para el estudio de la creación tanto de nuevas palabras y sintagmas, como de nuevos significados. En dicha propuesta se tiene en cuenta la organización en marcos o esquemas de las unidades lingüísticas y las unidades semánticas del texto.

Otro de los pioneros de la lingüística cognitiva es Langacker, creador de la gramática cognitiva de tendencia radicalmente opuesta a la gramática de corte generativista. Este autor la define como: "diverges from standard assumptions in two fundamental respects: (i) its claim that grammar is symbolic in nature; and (ii) its focus on constructions (rather than "rules") as the primary objects of description" (2009: 1). Así pues, la gramática cognitiva presenta el lexicón, la morfología y la sintaxis como un continuo que se dividen únicamente de manera arbitraria en componentes discretos y contempla como objetos de estudio entidades abstractas tales como los conceptos (1999; 2009). La aportación de Langacker no se reduce a la gramática cognitiva, sino que va más allá y presenta el término dominio cognitivo como: "is convenciently used for either a basic domain (as defined above) or a conceptualization of any kind of degree of complixity. We can saw, then, that a lexical item evokes a set of cognitive domains as the basis for its meaning, and exhibits considerable flexibility in the regard" (Langacker, 1999: 4).

Tras la presentación de algunas de las contribuciones que han marcado la historia de la lingüística cognitiva, debido a que el estudio que se presentará adopta la perspectiva diacrónica, se debe tener en cuenta la gramaticalización, concepto clave y en cierto modo relacionado con la fraseologización. La gramaticalización surge de las ideas neogramáticas y entre los diversos estudios que presentan dicho proceso, merecen mención especial Grammaticalization (Hopper y Traugott, 2003) y Regularity in semantic change (Traugott y Dasher, 2002). A continuación se presenta la concepción de gramaticalización que Hopper y Traugott postulan:

[...] Has two meanings, one to do with a research framework within which to account for language phenomena, the other with the phenomena themselves. In this respect the term 
"grammaticalization" resembles not only other terms in linguistics such as "grammar", "syntax", and "phonology", but the terminology of all higher, level concepts in scholarly disciplines. As a term referring to a research framework, "grammaticalization" refers to that part of the study of language change that is concerned with such questions as how lexical items and constructions come in certain linguistic contexts to serve grammatical functions or how grammatical items develop new grammatical functions. This research framework is also concerned with characterizing the subset of cross-linguistically recurring correlations across time among semantic-pragmatic, morphosyntactic, and (sometimes) phonological changes (Hopper y Trougott, 2003: 1).

De las palabras de Hopper y Traugott se desprende la caracterización minuciosa de qué se entiende por gramaticalización, no obstante, además de definir el proceso y sus características, estos autores presentan dos perspectivas desde las cuales se puede abordar la gramaticalización. La perspectiva diacrónica estudia los cambios que se producen, así como los diferentes pasos y estadios que explican la consolidación de una unidad. En cuanto a la segunda perspectiva, la sincrónica, estos autores resaltan el estudio de la sintaxis y del discurso pragmático.

La contribución de Heine y Kuteva no se puede obviar, pues tienen en cuenta la gramaticalización en lenguas de contacto e introducen el término "contact-induced grammaticalization" como "a grammaticalization process that is due to the influence of one language on other. We will distinguish two main types of contact-there exists already a model source-totarget grammaticalization process to be replicated" (2005: 80). Los cambios que caracterizan la gramaticalización son presentados por Heine y Kuteva (2005) como parámetros de gramaticalización y se distinguen cuatro: extensión, desemantización, descategorización y erosión. Así pues, un elemento se ha gramaticalizado cuando "a content word assumes the gramatical characteristics of a función word” (Hopper y Trougott, 2005: 4).

Para finalizar con la presentación grosso modo de la lingüística cognitiva, cabe destacar los mecanismos figurativos tales como la metáfora y la metonimia, objeto de estudio y mención en las obras de corte cognitivo desde el surgimiento de este movimiento (Lakoff y Johnson, 1980) hasta la actualidad. En el apartado siguiente se abordarán estos mecanismos, no obstante, se considera oportuno mencionar la metáfora y metonimia como integradoras del proceso de gramaticalización al que hemos aludido por contemplarse estrategias metafóricas para regular y negociar la comunicación entre hablantes y oyentes (Hopper y Traugott, 2003: 92-93).

\subsection{Los mecanismos figurativos. Cognición y fraseologización}

La metáfora como mecanismo cognitivo ha sido tratada por diferentes autores y estos han coincidido en la contemplación de dos dominios (Lakoff y Johnson, 1980; Croft y Cruce, 2004; Geeraerts, 2010; Cuenca y Hilferty, 2013). No obstante, la concepción tradicional de las figuras retóricas las vinculaba con la literatura, pues se concebían como el resultado de la creación artística de escritores. Esta es refutada por Lakoff y Johnson (1980) al plantear la metáfora como un mecanismo, en ocasiones convencionalizado, mediante el cual se procesa la información abstracta a partir de conceptos más simples y concretos. La teoría de la metáfora conceptual caracteriza este mecanismo cognitivo como un fenómeno en el que el dominio origen (DO) se representa conceptualmente en términos de otro (dominio destino). Así pues, se acerca la realidad al hablante mediante la presentación de lo abstracto en términos de lo concreto o corpóreo. Las metáforas conceptuales se hallan jerarquizadas y por ello, no es de 
extrañar que de una metáfora subyazga otra. Finalmente, en cuanto a este tipo de metáfora, cabe destacar que la proyección es parcial, pues son determinadas propiedades las que se proyectan de un dominio a otro. Además de la metáfora conceptual, Lakoff y Johnson (1980) distinguen la de imagen, división que postulan y desarrollan Cuenca y Hilferty (2013).

Asimismo, para Cuenca y Hilferty la metáfora conceptual proporciona un patrón para un sistema determinado de expresiones metafóricas, frente a la metáfora de imagen que se constituye a partir de la relación que se produce entre la imagen esquemática del dominio origen (DO) y el dominio destino (DD). A continuación se mostrarán metáforas conceptuales y de imagen con la finalidad de apreciar en casos particulares las características descritas (Cuenca y Hilferty, 2013: 101, 104):

(1) DO: LOS ALIMENTOS, DD: LAS IDEAS

¿Y eso cómo se come?

No me trago lo que me estás diciendo

Algo se está cociendo en la Moncloa

Me cuesta digerir tanta información

Italia es una bota

La proyección puede ser ontológica o epistémica, la primera vincula subestructuras entre los dos dominios, a diferencia de la epistémica que no presenta conexiones entre las subestructuras de los dominios, sino que representan el conocimiento importado del DO al DD. En (2) y (3) se muestran algunos de los ejemplos que estos autores presentan de la proyección ontológica y epistémica, respectivamente (2013: 102):

(2) Las ideas corresponden a los alimentos

La persona que come los alimentos corresponde a la persona que acepta la idea

Cocinar el alimento corresponde a concebir la idea

Digerir el alimento corresponde a comprender la idea

(3) Dominio origen: los alimentos sustentan el cuerpo

Dominio destino: las ideas sustentan la mente

Los casos (2) y (3) presentan los dos tipos de proyección, en (2) se produce la relación analógica entre las partes más relevantes de cada dominio, mientras que en (3) se ponen de manifiesto las intuiciones extraídas del DO.

La metonimia, al igual que la metáfora, se concibe como un fenómeno conceptual y en este mecanismo aparece el término punto de acceso mental, a través del cual se accede a la información y comprensión del domino (Langacker, 1999). Son varias las concepciones que de esta se tiene; por un lado, hallamos la consideración de que toda metonimia es necesariamente referencial (Croft y Cruce, 2004), y por otro, la concepción de que dicho mecanismos suele ser referencial pero también cabe la posibilidad de que no lo sea. En los primeros estudios metonímicos, Lakoff y Johnson (1980) la dotan de referencialidad, pero, además, la muestran como fundamental para la representación y comprensión de la realidad.

La metonimia opera en un solo dominio, en concreto, en un dominio funcional. No basta con que la fuente y la meta se hallen en el mismo dominio, sino que según Fauconnier 
(1994), deben estar conectadas mediante proyecciones con función pragmática. Peirsman y Geeraerts (2006) presentan los diferentes tipos de metonimia en función de la prototipicidad de estas. De este modo, las más prototípicas son aquellas que operan en el domino espacial y material, mientras que en la periferia se hallan las que actúan en el dominio de los "grupos y colecciones" de entidades.

Con anterioridad se mencionó la adopción de la obra de Cuenca y Hilferty como pilar para comprender la metaforización de de boca en boca. Asimismo, a continuación se presentará la metonimia desde la concepción de estos autores, debido a que será la que se tenga en cuenta para el análisis metonímico de la unidad fraseológica. Así pues, la metonimia es la referencia indirecta que alude a la entidad implícita a través de otra explícita, es decir, asocia dos entidades que conceptualmente son contiguas y pertenecen al mismo dominio. Al respecto, cabe destacar dos conceptos clave: el punto de referencia (PR) y la zona activa (ZA). A continuación se muestra la clasificación de las principales metonimias llevada a cabo por Cuenca y Hilferty (2013: 112):

1. La parte por el todo

2. El todo por la parte

3. El contenido por el continente

4. La persona por su nombre

5. El lugar físico por la institución situada en ese lugar

6. La institución por las personas responsables

7. El productor por el producto

8. El controlador por sus subordinados

Expuestas las diferentes concepciones de la metáfora y la metonimia, se cree oportuno hacer referencia al papel que los factores culturales pueden desempeñar en la aparición y creación de nuevas metáforas y metonimias. Asimismo, es importante tener presente que los mecanismos cognitivos presentados y descritos no son excluyentes, de hecho, en numerosas ocasiones la metáfora surgen a raíz de una metonimia, por lo que se observa la complementación y sucesión de estos mecanismos (Geeraerts, 2010).

Una vez se ha dado cuenta de las contribuciones sobre las metáforas y metonimias, se debe abordar la presencia de estos mecanismos figurativos en los estudios fraseológicos. Son ineludibles autores como Ruiz (2000; 2001), Adam (2007) y Olza (2011a; 2011b), entre otros, no obstante, antes de presentar los trabajos señalados, se debe hacer mención especial a la obra de Álvarez de la Granja Lenguaje figurado y motivación: una perspectiva desde la fraseología (2008) debido a la contemplación que en esta se hace de los mecanismos figurativos como procedimientos de creación de los fraseologismos, y por lo tanto, posibles procedimientos motivadores del sentido figurado de algunas UF. Esta obra es un pilar imprescindible para la realización de estudios que den cuenta de dichos mecanismos, pero, sobre todo si el estudio se realiza desde la perspectiva diacrónica. Expuesta la relevancia de la obra de Álvarez de la Granja (2008), se procede a la contemplación de estudios específicos donde se conjugan fraseología y mecanismos figurativos. Ruiz en "Las metáforas de un día en los medios de comunicación españoles" (2000) lleva a cabo el análisis de las metáforas en los medios de comunicación, y en concreto, se centra en la ruptura de la tregua de la banda terrorista ETA y cómo la prensa escrita y de radio cubren dicha noticia. Dichas metáforas convencionalizadas forman parte del universo fraseológico, pues aparecen fraseologismos como ponerse los pelos de punta (locución verbal coloquial). 
Las UF con núcleo somático o nombre de animal conllevan, además de cierta transparencia, la actuación de los procedimientos figurativos en su formación. Debemos centrarnos en las unidades fraseológicas somáticas (UFS) y los estudios que se han llevado a cabo por autores como Adam (2007) y Olza (2011a; 2011b), en los cuales se presenta como objeto de estudio las UFS y los mecanismos figurativos tales como la metáfora y la metonimia. Adam estudia los fraseologismos somáticos cuyo núcleo es boca, cara, mano, ojo o pie y se documentan en corpus españoles y polacos. Este trabajo es un claro ejemplo de fraseología contrastiva. Por otro lado, Olza (2011a) lleva a cabo la clasificación de las locuciones somáticas ${ }^{1}$ mediante el núcleo de las mismas. Se presentó con anterioridad la estrecha relación que poseen los mecanismos figurativos y la motivación de las UF, pero también se debe tener en cuenta que tal y como Olza (2011b) manifiesta, estos procedimientos están relacionados con la idiomaticidad de los fraseologismos. De hecho, en numerosas ocasiones los fraseologismos con un alto grado de idiomaticidad deben este rasgo al significado figurado adquirido mediante la intervención de mecanismos como la metáfora o la metonimia.

\section{Metodología}

Las UFS, al igual que el resto de fraseologismos, se adquieren en bloque a lo largo de nuestra vida y conforman nuestro saber enciclopédico. Son varios los estudios que versan sobre los FS (Ruiz, 2001; Olza, 2011a, 2011b), sin embargo, estos plantean un análisis sincrónico. Mediante el estudio sincrónico y diacrónico de la locución adverbial de boca en boca se pretende llevar a cabo una aproximación al estudio del fraseologismo y su fraseologización. En el proceso de fraseologización intervienen distintos mecanismos que ayudan a consolidar y fijar una expresión, se trata de los procedimientos figurativos y por ello, la base del análisis estriba en la intersección entre cognitivismo y fraseología. Sin duda, el estudio diacrónico de una UF fijada en la lengua no es tarea fácil y para obtener datos objetivos que permitan observar la fraseologización se recurrirá a tres corpus de referencia (CORDE, CREA y CORPES XXI).

\subsection{Definición funcional de la UF}

Conviene presentar las principales características de las UF para consolidar la base metodológica de nuestro análisis, pues el paso previo al análisis es plantear qué se entenderá por UF y qué características se deben tener en cuenta para abordar su estudio. Las propiedades por excelencia de los fraseologismos son la idiomaticidad y la fijación (Ruiz, 1997, 1998, 2001; López, 2002); no obstante, se debe tener en cuenta la aportación de Ruiz al respecto, pues esta autora presenta la fijación como propiedad necesaria y la idiomaticidad como subsidiaria y jerarquizada en grados (2001: 125-126). En el proceso de fraseologización tiene especial importancia la repetición de la combinación de palabras, pues mediante su reproducción esta se fija y se convierte en una unidad. Asimismo, "la reproducibilidad debe ser entendida en estos dos sentidos por un lado, como la causa de la formación de una UF y, por otro, como la consecuencia de otra de sus propiedades, la fijación" (López, 2002: 40); por lo que la idiomaticidad, la fijación y la reproducibilidad están interrelacionadas.

1 En dicho estudio se tiene en cuenta solo los fraseologismos considerados locuciones. 


\subsubsection{Idiomaticidad y motivación}

La idiomaticidad es una propiedad no necesaria y consiste en la no deducibilidad del significado global a raíz de la suma del significado de sus componentes (Corpas, 1996; Ruiz, 1998; López, 2002). Dicha propiedad está relacionada con el grado de motivación, tal y como manifiesta Olza:

El nivel de idiomaticidad de una UF se halla relacionado inversamente con el grado de motivación semántica que puede asociársele, esto es, con la transparencia que pueden ser percibidos los distintos mecanismos [...] responsables de su significado no composicional; por otro lado, la complejidad del entramado de esquemas figurativos en que se basa cada significado fraseológico es normalmente responsable de un grado mayor de idiomaticidad (Olza, 2011a: 112).

Esta característica es potencial y no esencial, por lo que en función de esta y de la motivación se pueden distinguir dos tipos de fraseologismos: los prototípicos y los periféricos (Ruiz, 2001; López, 2002). Respecto a la motivación, Álvarez de la Granja (2008) contempla dos tipos de motivación: la externa se basa en la relación entre el significado y la forma significante; y la interna que se origina en el interior del sistema de la lengua y presenta dos tipos (motivación morfológica y paronímica). Otro tipo de motivación es la semántica y para el análisis deberemos tener en cuenta la motivación paronímica y la semántica, pues la primera contempla la homonimia y la segunda, en palabras de Álvarez de la Granja, “designa en la realidad un objeto o concepto con el que lo designado por el primero presenta o una relación de analogía o semejanza, o una relación de carácter extralingüístico [...] basada en asociaciones entre signos que designan objetos o conceptos que están relacionados de alguna manera en la realidad" (Álvarez de la Granja, 2008: 65).

La idiomaticidad puede estar ligada a los mecanismos figurativos y en el análisis de las locuciones somáticas se pretende comprobar cómo mediante determinados tropos se confecciona la UFS de boca en boca. Al respecto se debe tener en cuenta la aportación de Cuenca y Hilferty sobre la idiomaticidad:

En el fondo, la idiomaticidad se basa en la posibilidad de sacar provecho de facetas asociativas de nuestro conocimiento del mundo con el fin de proyectar la situación que éstas representan sobre otra de índole análoga. En muchas ocasiones, estas asociaciones se derivan de nuestros modelos cognitivos, cuya naturaleza idealizada nos permite sacar el sentido pertinente de la expresión en cuestión (Cuenca y Hilferty, 2013: 119).

Los mecanismos figurativos más productivos son la metáfora y la metonimia y estos se tendrán en cuenta en la realización del análisis, asimismo, es posible su complementación y sucesión. De hecho, la metonimia se llega a concebir como la motivadora de las metáforas, es decir, el mecanismo desencadenante de otro mecanismo figurativo, como es el caso de la metáfora. Esta concatenación se podrá comprobar a lo largo del estudio que se lleva a cabo, pues en numerosas ocasiones la variación de una variante de la UF de boca en boca se explica mediante la sucesión de estos mecanismos. 


\subsubsection{Fijación y reproducibilidad}

La fraseologización se suele definir como el proceso mediante el cual se constituye una UF y en este intervienen la idiomaticidad, la fijación y la reproducibilidad. Las UF nacen del uso y repetición de estructuras formadas por varias palabras (combinación libre) y a raíz del uso en contextos determinados se llega a la estabilidad y fijación tanto estructural como semántica. Así pues, nos encontramos ante una combinación fija con significado figurado y con cierto grado de idiomaticidad. Se debe destacar la importancia que tiene el respaldo de la sociedad mediante la repetición de la estructura, pues así es como se fija, mediante la memorización y repetición en bloque.

\subsubsection{Significado literal y significado figurado}

Es conveniente delimitar los dos significados que pueden presentar los fraseologismos, y por ello, en este apartado se pretende dar cuenta de qué se entenderá por significado literal y qué por figurado. Estos no se extrapolan, pues, pueden darse durante el proceso de fraseologización al convertirse una combinación libre de palabras (significado literal) en una unidad fija y estable debido a su significado no deducible de la suma de los significados de sus componentes. De ahí surge la idiomaticidad entendida como la superación del significado literal y conformación de combinaciones fijas de palabras (Ruiz, 2001), en ocasiones, producto de los procedimientos figurativos que crean y consolidan la UF.

Una vez planteados los dos significados y la relación que existe entre estos, debemos tener en cuenta el lexema boca y las acepciones que presenta como lema. Son varias las obras lexicográficas que se han consultado ${ }^{2}$, no obstante, se seguirá el Diccionario del español actual (DEA) debido a que los autores de este también lo son del Diccionario fraseológico documentado del español actual (DFDEA), diccionario que se tendrá en cuenta a la hora de discernir el significado fraseológico de la locución. Mediante esta decisión se pretende dotar al estudio de coherencia y evitar controversias en torno a las diferentes entradas lexicográficas que presentan los diversos diccionarios. A continuación se muestran las acepciones correspondientes al lema boca que se tendrán en cuenta para nuestro estudio, así como la clasificación de estas en significado literal o figurado:

\begin{tabular}{|l|l|}
\hline \multicolumn{1}{|c|}{ Significado literal } & \multicolumn{1}{c|}{ Significado figurado } \\
\hline Órgano del habla. & $\begin{array}{l}\text { Loc adj } \sim \text { a } \sim: \text { :Respiración] provocada en una } \\
\text { persona accidentada, consistente en aplicar la } \\
\text { boca a la de esa persona para insuflarle aire } \\
\text { con un ritmo determinado. }\end{array}$ \\
\hline $\begin{array}{l}\text { Entrada o salida [de un lugar más o menos } \\
\text { estrecho o de una cavidad]. }\end{array}$ & $\begin{array}{l}\text { De } \sim \text { en } \sim: \text { Divulgándose en conversaciones } \\
\text { o comentarios, o en transmisión oral. Frec } \\
\text { con } v s \text { como ANDAR o CORRER. Tb adj. }\end{array}$ \\
\hline$\sim$ a $\sim$ : relación o transmisión oral directa. & \\
\hline
\end{tabular}

Figura 1: Boca y sus significados.

2 Los diccionarios generales que se han tenido en cuenta además del DEA son el Diccionario de la Real Academia Española (DRAE) y el Diccionario de uso del español (DUE). 
A pesar de que el lema boca ofrece 58 acepciones, en la figura 1 se presentan aquellas que podrían aparecer al estudiar la locución de boca en boca. Esta delimitación es el primer paso hacia la pavimentación del objeto de estudio y el segundo paso se llevará a cabo en el apartado 3.4., donde se abordará la problemática existente en torno a los límites entre locución adverbial y locución verbal.

\subsection{Variantes y variaciones: definiciones y clasificaciones}

En torno a la variante y la variación se observa homogeneidad entre varios autores, pues contemplan la variante como un fraseologismo que se halla en la misma lengua funcional, sin diferencia de significado y con una estructura y componentes semejantes a la UF; en cuanto a la variación, esta se presenta como el cambio de significado de una estructura semejante al fraseologismo (Zuluaga, 1980; Corpas, 1996; Mena y Corpas, 2003; Montoro del Arco, 2006).

Las variantes y variaciones han sido clasificadas por dos autores: García-Page $(2008)^{3}$ y Montoro del Arco (2006). La clasificación que se seguirá es la llevada a cabo por Montoro del Arco (2006) ya que este clasifica tanto las variantes como las variaciones. Es imprescindible mostrar qué entiende este autor por variante y variación antes de tratar su clasificación. Según Montoro del Arco, las variantes se dan en la misma lengua funcional que la UF, no presenta diferencia de sentido y son idénticas en su estructura y componentes. En cuanto a las variaciones, de la aportación de dicho autor cabe destacar el cambio de sentido que presentan. A continuación se ofrece grosso modo la clasificación de Montoro del Arco, pues debido a su complejidad es oportuno mostrar el esqueleto que vertebra su clasificación antes de proceder a la explicación de la misma:

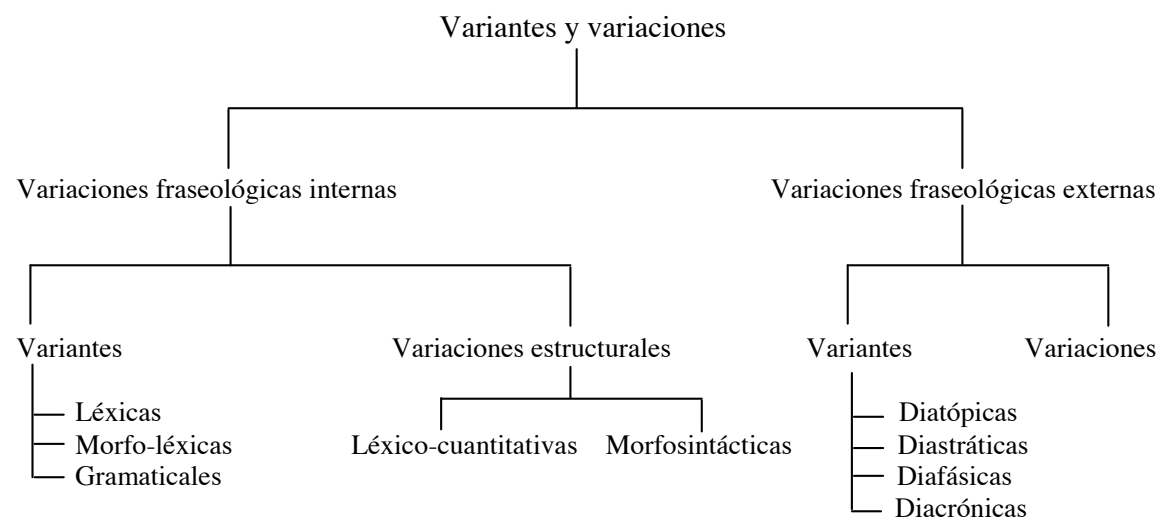

Figura 2: Clasificación de variantes y variaciones (Montoro del Arco, 2006).

La primera distinción que se lleva a cabo es clasificar las variaciones fraseológicas en internas y externas, así pues, debido a la envergadura de la clasificación, en primer lugar se presentarán las variaciones fraseológicas internas y los tipos de variantes y variaciones que hallamos en esta, y finalmente las variaciones fraseológicas externas y sus variantes y variaciones.

3 Este autor distingue tres variantes: variante gramatical, variante léxica y variante sintáctica. 
En las variaciones fraseológicas internas se distinguen tres tipos de variantes (variantes léxicas, morfo-léxicas y gramaticales) en función de la morfología presentada por el elemento sustituido:

Variantes léxicas: alteración de uno o varios componentes de la locución mediante la sustitución ya sea por un lexema o un sintagma. A su vez, dependiendo de la función que desempeña el elemento modificado se distinguen tres tipos de alteración: alteración del núcleo verbal, del núcleo nominal y de ambos núcleos.

Variantes morfo-léxicas: estos cambios se producen en la morfología derivativa o léxica al emplear sufijos o prefijos para crear superlativos, diminutivos o aumentativos.

Variantes gramaticales: es el tercer tipo y a pesar de la similitud que presenta con las variantes léxicas, la diferencia reside en que el componente estructural que se modifica es gramatical. Estas variantes gramaticales se pueden dar mediante dos procedimientos: la sustitución de la categoría morfológica de un segmento léxico (no pegar un ojo > no pegar los ojos), o bien mediante la sustitución de un elemento cuya función sea gramatical ${ }^{4}$.

Las variaciones estructurales articuladas bajo las variaciones fraseológicas internas son dos y estas a su vez se subdividen:

Variaciones léxico-cuantitativas: fraseologismos que admiten la reducción o el incremento de su estructura en función de la fijación y el inventario fraseológico que posea. Hallamos tres tipos de variaciones léxico-cuantitativas que son a) el incremento, sustracción y complementación (hilar [muy] fino); b) sintetización o variación gráfica (a bocajarro y a boca de jarro); y c) las citas interrumpidas fijadas, es decir, aquellos enunciados fraseológicos que no se enuncian al completo y su significado no se ve afectado debido a que el fraseologismo forma parte del conocimiento compartido de los hablantes (ojo por ojo...).

Variaciones morfosintácticas: Modificaciones producidas por la verificación de parte de los comportamientos libres de algún elemento del fraseologismo y estas modificaciones pueden ser a) cambios de género y número; b) alteración del orden y nominalización; y c) UF con casillas vacías que se rellenan con un elemento perteneciente a su paradigma (a mis/tus/sus anchas).

Las variaciones fraseológicas externas, al igual que ocurría con las internas, se dividen en variantes y variaciones. Las variantes que hallamos son léxicas y pueden ser a) diatópicas; b) diastráticas; c) diafásicas; y d) diacrónica. De estas cuatro la que más nos puede ayudar a lo largo del análisis es la cuarta, pues la lengua está en continuo cambio y puede haber variantes pertenecientes a distintas épocas que convivan durante una etapa de la evolución y consolidación del fraseologismo. En cuanto a las variaciones estructurales, estas se caracterizan por implicar varias lenguas funcionales y sería el caso de fraseologismos que están compuestos por lexemas pertenecientes al español peninsular y al hispanoamericano.

Al comienzo de este apartado se proporcionó la definición de variación propuesta por Montoro del Arco y tras presentar y desglosar su clasificación debemos realizar una anotación al respecto, pues algunas de las variaciones estructurales que este autor propone no afectan semánticamente al fraseologismo, como puede ser la variación léxico-cuantitativa. Incluso en

4 Se trata de las tradicionalmente llamadas partículas que abarca artículos, pronombres, preposiciones, etc. 
el ejemplo proporcionado por el propio autor (hilar [muy] fino) se observa que el cambio semántico es prácticamente inexistente. Al respecto, se debe tener en cuenta que los corpus nos proporcionarán casos en los que la variante se haya formado mediante un procedimiento considerado por Montoro del Arco como variación. De este modo, se producirá un choque entre la clasificación elegida y las ocurrencias que manifiestan los corpus, por lo que en dicho caso se optará por entender la variación como un procedimiento que en ocasiones complementa la formación de variantes y no siempre variación va ligada a cambio semántico.

\subsection{Corpus}

\subsubsection{Descripción}

Las UF, al igual que el resto de unidades que conforman el léxico del español, han evolucionado, pues la estructura y el significado actual pueden no coincidir con la primera datación de dicha unidad. La lengua no es estable, al menos en su totalidad, y por ello se recurre a la perspectiva diacrónica para trazar la fraseologización de la locución somática. El análisis debe sustentarse en datos objetivos de la evolución histórica del fraseologismo a lo largo de las distintas épocas y para ello se han utilizado tres corpus (CORDE, CREA y CORPES XXI) mediante los cuales se ha trazado la evolución de de boca en boca. No obstante, cada uno de estos corpus posee unas características determinadas que de una forma $\mathrm{u}$ otra han repercutido en la recopilación de datos.

La principal base de datos que proporciona una perspectiva diacrónica es el CORDE, pues a pesar de que se complementa con el CREA, esta última estaría a caballo entre la diacronía y la sincronía. Estos dos corpus plantean una serie de características que pueden favorecer la documentación de la locución o condicionar el planteamiento del estudio. Ambos poseen un motor de búsqueda que permite delimitar el período histórico, el país e incluso la autoría (para estudios de índole idiolectal). Estas son propiedades que favorecen la búsqueda, sin embargo, en ocasiones no se proporciona una fecha exacta, sino que se baraja un período temporal que en algunos casos puede abarcar dos siglos, pues este hecho se ha producido en varias ocasiones durante la extracción de casos. Esto nos obliga a tomar una decisión acerca de la datación en estos casos y por lo tanto, cuando un caso de de boca en boca se halle entre varios años se tendrá en cuenta la fecha más antigua.

El CORPES XXI complementa los datos del CREA y no es de extrañar que algunos casos extraídos del CREA aparezcan en el CORPES XXI al realizar la misma búsqueda, pues el CREA abarca años contemplados por el CORPES XXI (2001-2004); por ello, cuando suceda se tendrá en cuenta los casos del CREA. El CORPES XXI ofrece fechas exactas y un motor de búsqueda avanzado, no obstante, presenta un contexto reducido que en ocasiones dificulta la comprensión del fraseologismo.

Los tres corpus de referencia mostrados poseen representatividad en cuanto a la variedad geográfica, sin embargo, debido a la importancia del cognitivismo en los fraseologismos y las diferencias cognitivas que pueden presentar los hablantes de español de un lado del charco y del otro, se opta por delimitar el objeto de estudio a la variedad peninsular. Los corpus sincrónicos poseen documentación de la oralidad de los fraseologismos, sin embargo, nuestro estudio versará en torno a las ocurrencias registradas a lo largo de la historia mediante la escritura. 


\subsubsection{Obtención y filtración de datos}

Las características de los corpus que sustentan este trabajo ya han sido expuestas y a continuación se tratará el procedimiento que seguiremos tras la búsqueda de los fraseologismos en los corpus. Se contemplan diversas variables, sin embargo, antes de tratarlas una a una debemos tener en cuenta el cuadro que se presenta a continuación:

\begin{tabular}{|c|c|c|c|c|}
\hline Período de tiempo & Casos & Significado & Valor & Verbo \\
\hline \multicolumn{5}{|l|}{$1201-1250$} \\
\hline \multicolumn{5}{|l|}{$1251-1300$} \\
\hline \multicolumn{5}{|l|}{$1301-1350$} \\
\hline \multicolumn{5}{|l|}{$1351-1400$} \\
\hline \multicolumn{5}{|l|}{$1401-1450$} \\
\hline \multicolumn{5}{|l|}{$1451-1500$} \\
\hline \multicolumn{5}{|l|}{$1501-1550$} \\
\hline \multicolumn{5}{|l|}{$1551-1600$} \\
\hline \multicolumn{5}{|l|}{$1601-1650$} \\
\hline \multicolumn{5}{|l|}{$1651-1700$} \\
\hline \multicolumn{5}{|l|}{$1701-1750$} \\
\hline \multicolumn{5}{|l|}{$1751-1800$} \\
\hline \multicolumn{5}{|l|}{$1801-1850$} \\
\hline \multicolumn{5}{|l|}{$1851-1900$} \\
\hline \multicolumn{5}{|l|}{$1901-1950$} \\
\hline \multicolumn{5}{|l|}{$1951-2000$} \\
\hline $2001-2014$ & & & & \\
\hline
\end{tabular}

Figura 3: Tabla para los casos de de boca en boca.

Esta tabla reúne las variables que pueden sintetizar aquellos aspectos más relevantes para la primera aproximación al estudio fraseológico de de boca en boca. La figura 3 corresponde a boca a boca, y las minidiacronías comienzan en el siglo XIII debido a que su primera aparición se registra en la segunda mitad de dicho siglo. Dichas minidiacronías pueden variar en función de la fecha de aparición de cada variante.

Es conveniente llevar a cabo la distinción operativa entre significado y valor con la finalidad de evitar posibles conflictos entre dichos términos. La variable valor es abierta, no se trata de un inventario cerrado debido a que se entenderá por valor aquellos significados (figurados o literales) que en función del contexto pueden presentar un contenido semántico u otro. De este modo, los valores corresponden a las diferentes acepciones que las obras lexicográficas 
presentan (DFDEA y $D E A$ ). El siguiente cuadro (figura 4) se corresponde con la figura 3, no obstante, en este aparece la recopilación y clasificación de los casos de boca a boca:

\begin{tabular}{|c|c|c|c|c|}
\hline $\begin{array}{l}\text { Período de } \\
\text { tiempo }\end{array}$ & Casos & Significado & Valor & Verbo \\
\hline $1201-1250$ & - & - & - & - \\
\hline $1251-1300$ & 2 & $\begin{array}{l}\text { Literal }(0) \\
\text { Figurado (2) }\end{array}$ & Relación o transmisión oral directa & Fablare \\
\hline $1301-1350$ & - & - & - & - \\
\hline $1351-1400$ & 1 & $\begin{array}{l}\text { Literal }(0) \\
\text { Figurado (1) }\end{array}$ & Relación o transmisión oral directa & Fablare \\
\hline $1401-1450$ & 1 & $\begin{array}{l}\text { Literal (0) } \\
\text { Figurado (1) }\end{array}$ & $\begin{array}{l}\text { Divulgándose en conversaciones o comentarios, } \\
\text { o en transmisión oral }\end{array}$ & Recibir \\
\hline $1451-1500$ & - & - & - & - \\
\hline $1501-1550$ & 1 & $\begin{array}{l}\text { Literal }(0) \\
\text { Figurado (1) }\end{array}$ & $\begin{array}{l}\text { Divulgándose en conversaciones o comentarios, } \\
\text { o en transmisión oral }\end{array}$ & Oír \\
\hline $1551-1600$ & 4 & $\begin{array}{l}\text { Literal }(0) \\
\text { Figurado (4) }\end{array}$ & Relación o transmisión oral directa (4) & Hablar (2) \\
\hline $1601-1650$ & $\begin{array}{l}6 \\
4\end{array}$ & $\begin{array}{l}\text { Literal (2) } \\
\text { Figurado (2) }\end{array}$ & $\begin{array}{l}\text { Relación o transmisión oral directa (2) } \\
\text { Contacto de una boca con la otra(2) }\end{array}$ & $\begin{array}{l}\text { Hablar } \\
\text { Juntar } \\
\text { Informar } \\
\text { Atar }\end{array}$ \\
\hline $1651-1700$ & 1 & $\begin{array}{l}\text { Literal }(0) \\
\text { Figurado (1) }\end{array}$ & Relación o transmisión oral directa & $\varnothing$ \\
\hline $1701-1750$ & - & - & - & - \\
\hline $1751-1800$ & - & - & - & - \\
\hline $1801-1850$ & - & - & - & - \\
\hline $1851-1900$ & - & - & - & - \\
\hline $1901-1950$ & 7 & $\begin{array}{l}\text { Literal (3) } \\
\text { Figurado (4) }\end{array}$ & $\begin{array}{l}\text { Relación o transmisión oral directa (4) } \\
\text { Contacto de una cavidad bucal con otra (3) }\end{array}$ & $\begin{array}{l}\text { Unir (1) } \\
\text { Hablar (4) } \\
\varnothing\end{array}$ \\
\hline $1951-2000$ & 64 & $\begin{array}{l}\text { Literal (37) } \\
\text { Figurado (27) }\end{array}$ & $\begin{array}{l}\text { Divulgándose en conversaciones o comentarios, } \\
\text { o en transmisión oral (24) } \\
\text { Relación o transmisión oral directa (1) } \\
\text { [Respiración] provocada en una persona } \\
\text { accidentada, consistente en aplicar la boca a la } \\
\text { de esa persona para insuflarle aire con un ritmo } \\
\text { determinado } \\
\text { (35) }\end{array}$ & $\begin{array}{l}\text { Comunicar (1) } \\
\text { Enviar }(1) \\
\text { Hacer }(16) \\
\text { Practicar }(7) \\
\text { Recorrer }(1) \\
\text { Iniciar }(1) \\
\text { Reanimar (1) } \\
\text { Saber }(1) \\
\text { Ser }(1) \\
\text { Pasar }(1) \\
\varnothing(1) \\
\varnothing(13)\end{array}$ \\
\hline
\end{tabular}




\begin{tabular}{|c|c|c|c|c|}
\hline & & & $\begin{array}{l}\text { Saludo oral (1) } \\
\text { Personas que reciben información de manera } \\
\text { oral (1) } \\
\text { Transmisión de un líquido u objeto de una } \\
\text { cavidad bucal a otra (2) }\end{array}$ & $\begin{array}{l}\varnothing(8) \\
\text { Difundir (1) } \\
\text { Aplicar (1) } \\
\text { Funcionar (2) } \\
\text { Salvar (1) } \\
\text { Generar (1) } \\
\text { Transmitir (1) } \\
\text { Aprobar (1) } \\
\text { Usar (1) } \\
\text { Correr } \\
\text { Ser }\end{array}$ \\
\hline 2001-2014 & 16 & $\begin{array}{l}\text { Literal (0) } \\
\text { Figurado (16) }\end{array}$ & $\begin{array}{l}\text { Divulgándose en conversaciones o comentarios, } \\
\text { o en transmisión oral (11) } \\
\text { [Respiración] provocada en una persona acci- } \\
\text { dentada, consistente en aplicar la boca a la de } \\
\text { esa persona para insuflarle aire con un ritmo } \\
\text { determinado (5) }\end{array}$ & $\begin{array}{l}\text { Funcionar (1) } \\
\text { Resucitar (1) } \\
\text { Hacer }(2) \\
\varnothing(2) \\
\varnothing(5) \\
\text { Hacer }(1) \\
\varnothing(2) \\
\text { Existir (1) } \\
\text { Correr(1) }\end{array}$ \\
\hline
\end{tabular}

Figura 4: Casos de boca a boca.

Observamos cómo el significado de boca a boca solo puede ser literal o figurado, mientras que en la columna valor se presenta disparidad de acepciones. Los datos obtenidos se han almacenado en un documento de Access y en este se contemplan diversas variables que pueden resultar de gran utilidad para el análisis de los casos y el trazado de la fraseologización. A las variables que los corpus CORDE y CREA presentan como predeterminadas (siglo, año, tema y autor) se le añaden en el documento de Access otros campos como son: a) corpus; b) UF, variante, variación o combinación libre; c) forma/estructura; d) contexto; e) observaciones; y f) palabras clave.

\subsection{La unidad de análisis: delimitación y procedimiento de análisis}

A lo largo de los apartados anteriores se ha proporcionado información sobre aspectos relacionados con el objeto de estudio y su investigación. En el presente apartado se delimitará la locución somática, la problemática en torno a su catalogación como locución adverbial o verbal y su perspectiva de análisis.

De boca en boca es un binomio prepositivo formado por la estructura PREP $+\mathrm{N}+$ PREP +N y al respecto García-Page (2008: 123) presenta dos correlaciones prepositivas con carácter fijo y cuyos huecos léxicos son cubiertos por sustantivos escuetos; las más frecuentes son: $d e \sim e n \sim$ y de $\sim a \sim$. La primera de ellas es la que se observa en de boca en boca, no obstante, no se debe pasar por alto la segunda estructura, pues la alternancia entre la preposición en y $a$ es habitual en diferentes épocas y puede haberse producido dicha conmutación en la evolución del fraseologismo. El esquema de $\sim$ en presenta el significado 'con una determinada frecuencia' y $d e \sim a \sim$ como 'totalidad espacial o temporal' por lo que 
nuestra UFS presenta en cierto modo el significado que García-Page plantea al producirse en de boca en boca una repetición o divulgación de información que conlleva la realización de dicha acción en varias ocasiones.

Para discernir qué tipo de locución es de boca en boca se debe tener en cuenta si en los corpus esta UF aparece con verbo y qué tipo de verbo. Para ello resulta imprescindible acudir a los diccionarios fraseológicos, pues deben ser estos los que mediante la institucionalización del fraseologismo arrojen luz a esta cuestión. A pesar de que parece una tarea fácil, al consultar las obras lexicográficas de carácter específico (diccionarios fraseológicos tales como el DELE, DFDEA, DFEM y DFSO) no se obtuvo la unanimidad que se esperaba:

\begin{tabular}{|l|l|l|}
\hline DFSO (1921) & \multicolumn{1}{|c|}{ Locución adverbial } & \multicolumn{1}{c|}{ Locución verbal } \\
\hline DFEM (1996) & \multicolumn{1}{|c|}{-} \\
\hline DFDEA (2004) & $\begin{array}{l}\text { De boca en boca: } \\
\text { adv Divulgándose en } \\
\text { conversaciones o comentarios, } \\
\text { o en transmisión oral. Frec con } \\
\text { vs como andar o correr. }\end{array}$ & $\begin{array}{l}\text { Andar u.c. de boca en boca (f.). Ser } \\
\text { de dominio público, propagarse. } \\
\text { Andar/estar u.p./u.c. en boca(s) de } \\
\text { alguien (inf.). Ser objeto de la mur- } \\
\text { muración de alguien. }\end{array}$ \\
\hline DELE (2009) & \multicolumn{1}{|c|}{$\begin{array}{l}\text { De boca en boca: } \\
\text { andar/correr/propagarse [algo] de } \\
\text { boca en boca; [loc. verb.] (col) (f). } \\
\text { propagarse/andar/ correr de persona } \\
\text { a persona, oralmente. }\end{array}$} \\
\hline
\end{tabular}

Figura 5: De boca en boca en las obras lexicográficas.

De las tres obras lexicográficas que recogen la locución que nos ocupa, se seguirá el $D F D E A$ puesto que son los autores que confeccionaron el diccionario general que se tuvo en cuenta para la obtención y clasificación de los significados de boca. Asimismo, se deben tener en cuenta los datos proporcionados por los corpus y si de boca en boca aparece con o sin verbo, ya que el uso registrado del fraseologismo muestra cómo se contempla esta locución, si como adverbial o como verbal. En la base de datos realizada se presentan los casos obtenidos y no hay unanimidad, puesto que hay casos en los que la locución no aparece con un verbo, aparece con los verbos mencionados en las obras lexicográficas o con otros verbos que no se tienen en cuenta en dichas obras.

No es de extrañar que en las diversas etapas de la lengua la UF que nos ocupa conviva con otras formas, ya sean variantes o variaciones de una variante de la UF. Los corpus sincrónicos muestran que hay varias estructuras coetáneas a de boca en boca en la actualidad y estas se 
registran en los diccionarios actuales como fraseologismos o variantes. Esta contemporaneidad nos da pie a realizar el análisis partiendo de la sincronía, por lo que de boca en boca en nuestro estudio se contemplará como UF y en función de si hay cambio semántico o no se articularán las variaciones y variantes. Independientemente de la perspectiva que se postule a la hora de abordar la locución, se parte de la primera aparición de esta para observar los posibles cambios semánticos y variaciones estructurales. Debido al número de casos que presenta de boca en boca (438) en el siguiente apartado se analizarán varios casos por siglo.

Con este trabajo se pretende realizar un acercamiento diacrónico y sincrónico a la locución somática mediante la complementación entre fraseología y cognitivismo, por ello, se realizará el análisis desde la perspectiva fraseológica (variaciones y variantes estructurales) y simultáneamente se adoptará la perspectiva cognitiva para arrojar luz a la aparición y fijación de las combinaciones de palabras. De este modo, el análisis propiamente fraseológico se llevará a cabo bajo las directrices de Montoro del Arco (2006) y su clasificación; mientras que para abordar la fraseologización desde la perspectiva cognitiva se seguirá a Cuenca y Hilferty (2013).

\section{Análisis: hacia la fraseologización de de boca en boca}

Tras la recopilación de datos se procede a la realización del análisis cuantitativo y cualitativo de las ocurrencias del fraseologismo, sus variantes, sus variaciones y sus combinaciones libres. Para realizar el análisis se dividirá este en varios siglos con la finalidad de observar detenidamente el proceso de fraseologización. Dicho análisis se llevará a cabo mediante la contemplación de varios aspectos: se trazará el proceso evolutivo mediante la contemplación de las diferentes estructuras y simultáneamente se abordará la locución desde la perspectiva cognitivista, mediante las asociaciones lingüísticas y extralingüísticas.

El FS de boca en boca presenta un total de 438 casos entre UF, variantes, variaciones y combinaciones libres; el número elevado de casos propicia la contemplación del análisis mediante la división y agrupación de siglos en función de los casos y los cambios semánticos y estructurales que se produzcan. A lo largo de la historia del fraseologismo este ha coexistido con diversas formas y se debe tener en cuenta las obras lexicográficas sincrónicas para observar qué fraseologismos en la actualidad podrían ser considerados como variantes de de boca en boca. A continuación se muestran algunas de las UF que el DFDEA presenta en la entrada correspondiente a boca y que pueden ser o pudieron ser variantes de nuestro objeto de estudio:

De boca a boca $\rightarrow$ BOCA A BOCA [3]

Correr de boca en boca $\rightarrow$ DE BOCA EN BOCA

De boca en boca. $a d v$ Divulgándose en conversaciones o comentarios, o en transmisión oral. Frec con vs como andar o correr. Tb adj. \| Mas-Matute Literatura 47: Existen dos clases de fábulas, las milesias... y aquellas que corren de boca en boca, llamadas apólogas. D Plaja Literatura 99: El trasiego de boca en boca origina que de cada romance se encuentren infinidad de versiones (Seco, 2004: 191).

Boca a boca. adj [Respiración] provocada en una persona accidentada, consistente en aplicarle aire con un ritmo determinado. \| Gac 11.5.69, 74: Se arrodillaron y en un instante comenzaron a aplicar la respiración boca a boca. 2 boca a boca. $m$ Respiración boca a boca $\|$ Yo le hubiera hecho con gusto el boca a boca..., todo menos dejarle ir así. 3 boca a boca (o, más raro, de boca a boca). $a d v$ En conversaciones o comentarios, o en transmisión oral. Tb adj. \|A.R. Sánchez Ver 23.2.21 (In): El buen hacer que se transmite boca 
a boca será tu mejor publicidad. Alegre Locus 75 (C): dice que las mujeres van a sentirse ofendidas, y eso es bueno, porque hoy por hoy siguen siendo la mejor propaganda boca a boca de un producto. M. Gómez SEIM 9.5.99 (In): La publicidad boca a boca es lo que mejor funciona en estas situaciones. Matute Gadú 680: Terroríficas leyendas propagadas boca a boca. 4 boca a boca. $m$ Relación o transmisión oral directall C. Santos D16 1.5.83,8: Antonio Garrígues sigue haciendo la campaña en la calle. Cada día dedica siete u ocho horas al "boca a boca", el contacto directo con los electores (Seco, 2004: 190).

De boca a boca presenta el mismo valor que boca a boca en su tercera acepción ('en conversaciones o comentarios, o en transmisión oral') por lo que en algún momento de la historia de la lengua estos dos fraseologismos han convergido. La información obtenida del DFDEA nos muestra que boca a boca y de boca a boca se asemejan a la locución somática de boca en boca en la forma y el significado. En la siguiente tabla se muestran los casos por siglo de UF, variantes, variaciones y combinaciones libres de de boca en boca:

\begin{tabular}{|c|c|}
\hline Siglo & Casos \\
\hline XIII & 2 \\
\hline XIV & 1 \\
\hline XV & 3 \\
\hline XVI & 21 \\
\hline XVII & 22 \\
\hline XVIII & 10 \\
\hline XIX & 107 \\
\hline XX & 241 \\
\hline XXI & 31 \\
\hline $\mathbf{4 3 8}$ & \\
\hline
\end{tabular}

Figura 6: Casos por siglo.

Tal y como se mencionó con anterioridad, el análisis se llevará a cabo mediante la división en subapartados que comprendan varios siglos. Así pues, una vez mostrados los casos agrupados en siglos y las posibles variantes, se procede a la realización del análisis.

\subsection{Siglos XIII, XIV, XV, XVI y XVII}

A lo largo de los siglos XIII, XIV, XV, XVI y XVII hallamos 49 casos que aparecen entre el 1260 y 1698 . En el siglo XIII se registran dos casos de boca a boca cuyo valor dista del actual significado:

$(4)^{5}$ Muchas cosas uos ouiera a escreuir, mas no quis con tinta ni con pennola, ca te cuedo ueer ayna, e fablaremos boca a boca. Paz sea contigo. Saludan te los amigos. Saluda tu a nuestros amigos, a cada uno por si.

5 Los ejemplos que se mostrarán y analizarán en este apartado han sido extraídos de los corpus de referencia diacrónicos y sincrónicos. 
(5) Mas el mi sieruo

moysen no es tal car en toda mi casa es muy

fiel. [8] Car boca a boca fablo con el \&

paladino \& non por espeios vee el

adios nin por figuras. Pues porque non

temiestes dezir mal del mi sieruo moysen.

Los casos (4) y (5) presentan una variación de la variante boca a boca al manifestarse un significado figurado distinto al de la variante: 'relación o transmisión oral directa'. La estructura boca a boca presenta un significado global que en principio no se podría discernir del significado de cada componente; no obstante, el hecho de que este fraseologismo posea un homónimo literal ayuda a intuir su significado figurado. Dicho significado figurado se ha formado a raíz de la intervención de mecanismos figurativos (Cuenca y Hilferty, 2013), por lo que se procederá al análisis de dichos mecanismos que han dado como resultado el significado figurado de boca a boca con el valor 'relación o transmisión oral directa'. En el proceso de creación del significado figurado que presentan los casos (4) y (5) en boca a boca se produce dos procesos metonímicos y uno metafórico cuyo resultado es la acepción 'relación o transmisión oral directa', a continuación se muestran y explican dichos mecanismos figurativos:

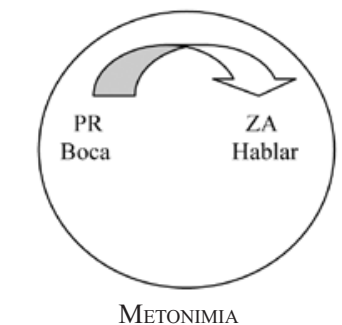

EL ÓRGANO POR LA FUNCIÓN
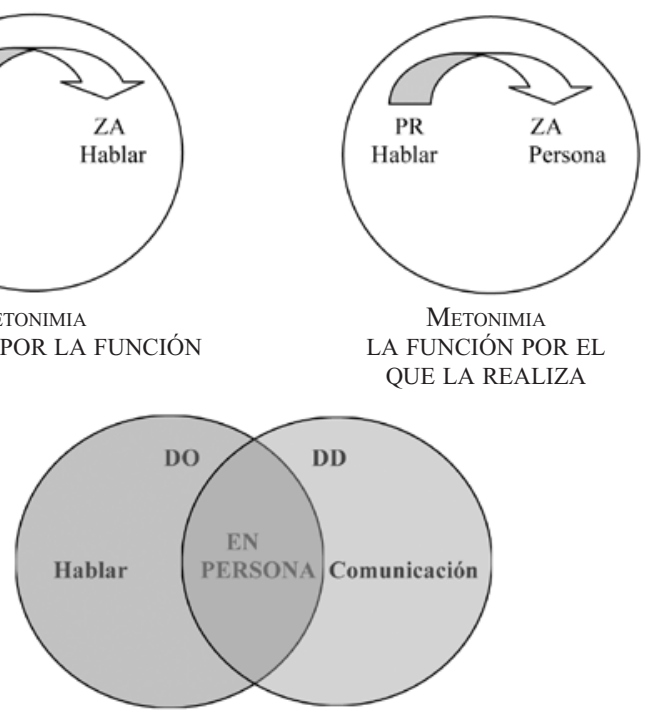

METÁForiZACIÓN DE LA RELACIÓN ENTRE LA COMUNICACIÓN VERBAL Y LA PRESENCIA

Figura 7: Procesos metonímicos y metafóricos de boca a boca.

En la figura 7 se presentan los tres procedimientos figurativos, dos metonimias y una metáfora. En cuanto a las primeras, se caracterizan por referirse a una estructura implícita (ZA) a través de otra explícita (PR), en concreto hallamos en a) EL ÓRGANO POR LA FUNCIÓN y en b) LA FUNCIÓN POR EL QUE LA REALIZA. La metáfora, al contrario que la metonimia, asocia entidades pertenecientes a dominios distintos (DO-DD) y de dicha proyección subyace una entidad, en este caso de la asociación hablar-comunicación obtenemos 'en persona', 
pues en el siglo XIII las conversaciones solo podían realizarse en presencia del otro. En cuanto al papel que esta locución desempeña, se puede observar en los ejemplos que el fraseologismo se presenta como una forma concreta de hablar y equivalente a una conversación presencial.

Esta variación manifiesta supremacía hasta el siglo XIV, pues no será hasta el siglo XV cuando dicha variación coexista con otras formas como la UF y las variantes boca a boca y de boca a boca. La variante gramatical boca a boca aparece en el 1450 con el significado figurado 'en conversaciones o comentarios, o en transmisión oral'. Esta variante es gramatical debido a la sustitución de la preposición en por $a(e n>a)^{6}$ y también se produce una variación estructural léxico-cuantitativa por reducción al desaparecer la preposición de sin que el significado global varíe:

(6) Y las partes que son escriptas de fuera de vna manera y dentro de otra, que es vn secreto diuino que ynporta grande misterio, y otras cosas del rresçebimiento i que son entregadas solamente a la Ley rresçebida boca a boca?, Así es dicho sobre los versos, que dize: "A mis leies guardaredes, $i$ la Ley escripta y la Ley del rresçebimiento" lo qual es allende de la escriptura fasta que fizieron saber en el Maçoret que la Vaf de Gahon es la meytad de la cuenta de la Ley, letra por letra, para enseñar el estudio que touieron en las cosas rresçebidas y la vnidat del misterio postrimero de la cuenta de las letras todas juntas, el qual non se conternía en ellos sy vna sola fallesçiese u ouiese sobrada otra.

El caso (6) es una variante gramatical y presenta una variación léxico-cuantitativa por reducción sin que esta repercuta en el significado del fraseologismo, pues Montoro del Arco presenta este tipo de variación como producto de la fijación del inventario de constituyentes y por ello, el significado no ha variado. La variante que se muestra en el ejemplo hace referencia al modo de recibir información de manera indirecta, pues la noticia se expande y comparte de manera oral y de unos a otros (ver apartado 4.4.).

La última ocurrencia que hallamos en este siglo se documenta a finales (c 1499-1502) y esta representa la primera documentación de la unidad fraseológica de boca en boca cuyo significado figurado es 'divulgándose en conversaciones o comentarios, o en transmisión oral':

(7) Pues yo bien siento mi honra. Pluguiera a Dios que fuera yo ellos y perdiera la vida, y no la honra y no la esperanza de conseguir mi comenzado propósito, que es lo que más en este caso desastrado siento. ¡Oh mi triste nombre y fama, cómo andas al tablero de boca en boca! ¡Oh mis secretos más secretos, cuán públicos andarés por las plazas y mercados!

El mecanismo figurativo que interviene en la UF y las variantes no se ha expuesto con anterioridad por resultar más adecuado realizarlo una vez se hayan visto las variantes que coexisten con la UF. De este modo, a continuación se presenta un ejemplo de la variante de boca a boca:

(8) $[\ldots] \&$ asi convjene que de entonçes fasta oy non se çeso de se rresçbir de boca a boca sin se escreujr jamas en libro.

6 Esta conmutación es habitual, pues así lo manifiesta Coromines (1980-1991) al hacer hincapié en la alternancia que se produce entre estas dos preposiciones utilizadas indistintamente. 
De boca a boca, al igual que la variante, boca a boca (6), hace referencia al modo de recibir una información de manera oral. Las preposiciones de y a que aparecen en la variante (8) manifiestan la circulación de la información que estaba en un punto inicial y se dirige hacia otro punto, otro destinatario. La LS de boca a boca se conforma y fija mediante la metonimia LA PARTE POR EL TODO y la metaforización de la oralidad conjugada entre el DO boca y el DD comunicación:
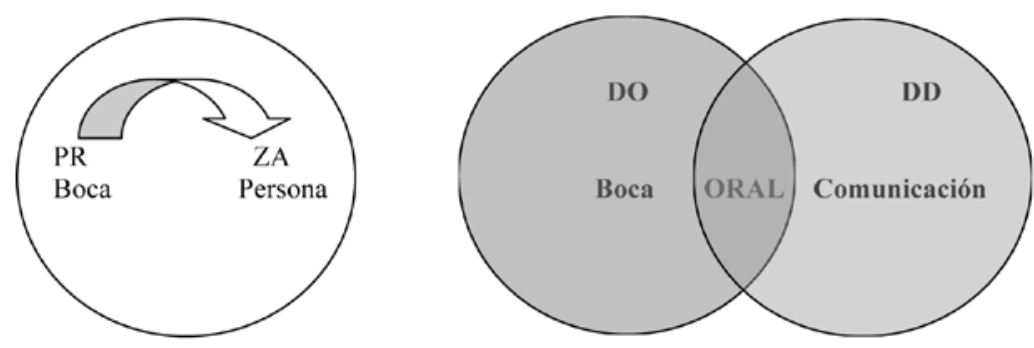

Figura 8: Metonimización y metaforización de de boca a boca.

En los esquemas anteriores se puede apreciar el proceso metonímico mediante el cual aparece el órgano en vez de la persona que lo posee, por lo que tras de boca a boca subyace la acción de una persona a otra. Dicha acción llevada a cabo por el órgano es el resultado de la asociación del DO y el DD, se trata de la oralidad, de la transmisión oral de una persona a otra.

A partir del siglo XVI el número de casos aumenta de manera considerable, pues hallamos 21 casos frente a los 2 o 3 que se manifestaban en los siglos anteriores. En este siglo coexiste la UF con diversas variaciones (de boca a boca, de boca en boca y boca a boca) y con la variante de boca a boca. En la década de los treinta hay un par de casos de la UFS junto a boca a boca (variación) y de boca a boca como combinación libre. La primera combinación libre de de boca a boca presenta el significado literal 'de una cavidad a otra':

(9) Asi que, resumiendo este camino, digo que desde el estrecho de Magallanes, costa a costa, hasta la Equinocial y cabo Blanco (por donde de ella pasa en la Tierra Firme en la parte oriental), hay, contando asimesmo las ciento e diez leguas del mesmo Estrecho (de boca a boca en su longitud), mill e seiscientas e cuatro leguas. Pero más de dos mill serán de navegar para lo andar.

En el 1549 aparece la primera variación de de boca en boca cuyo significado figurado dista del proporcionado por la UF, tan solo conserva la direccionalidad proporcionada por las preposiciones:

(10) Anda la cabra de roca en roca, como el bostezo de boca en boca.

La ocurrencia (10) es una variación de la UF cuyo significado es 'contagiar', pero este contagio no se realiza mediante el contacto de una cavidad con otra, sino que se lleva a cabo 
por el aire. Esta variación es producto de la metonimia EL ÓRGANO POR LA PERSONA QUE REALIZA LA ACCIÓN, pues el contagio del bostezo se realiza de persona en persona sin que haya contacto entre estas:

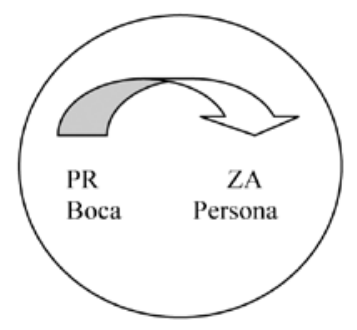

Figura 9: Metonimia de de boca en boca ('contagiar').

A mediados de siglo aparecen varios casos de la UF y será a finales cuando además de observar casos de la variación boca a boca (ver figura 7) vuelva a aparecer la variante gramatical por permutación de boca a boca. En el siglo XVI aparecen diversas estructuras coexistentes (las variaciones boca a boca, de boca a boca y de boca en boca, y la variante de boca a boca) y esta disparidad de estructuras se prolongará hasta el XVII. A pesar de que en el siglo XVII no aparecen las variantes, por el contrario, se muestra la hegemonía de la UF, pues más de la mitad de las ocurrencias son de de boca en boca. Este siglo presenta dos novedades, en primer lugar, el aumento de combinaciones libres con la estructura boca a boca y de boca a boca; y por otro lado, la aparición de la variación de la variante diacrónica voca a voca:

\section{(11) Que me digas pluma a pluma, por no poder voca a voca, que tienes otro devoto.}

En (11) voca a voca es una variación al tratarse de una acción llevada a cabo de manera presencial, pero, esta variación ya se produjo en el siglo XIII con la variación de la variante boca a boca. Boca a boca y voca a voca están relacionadas, pues esta última podría ser una variante fraseológica externa diacrónica de la primera al presentar cambios ortográficos propios de la época y la coexistencia de estas dos variantes en la diacronía.

\subsection{Siglos XVIII y XIX}

En el siglo XVIII el número de casos se reduce por primera vez mientras que el siglo XIX es un siglo prolífico en cuanto al número de ocurrencias, pues dicha cifra supera la centena. De los casos registrados en el siglo XVIII, el 90\% pertenecen a la UF (aparecen en la década de los treinta y setenta) y el $10 \%$ restante corresponde a una combinación libre cuya estructura es de boca a boca. A partir del siglo XIX se observa un notable incremento de ocurrencias al superar el centenar de casos proporcionados por el corpus diacrónico de referencia. En este período coexisten variantes, variaciones, combinaciones libres y la UF, no obstante, es digna de resalte la abundancia de ocurrencias de la UF por conformar casi un $94 \%$ de los casos con un total de 100 casos frente a las combinaciones libres de palabras 
(4 casos), dos ocurrencia de las variantes de boca en boca y de boca a boca, y una variación de la UF. A continuación se mostrará un caso de combinación libre, pues el número de ocurrencias de estas ha aumentado considerablemente en este siglo:

\section{(12) El estrecho les pareció que tenia cien leguas de boca á boca.}

Este es el primer caso de combinación libre registrado en este siglo y se diferencia del resto de combinaciones libres con las que coexiste en la segunda preposición, ya que $a$ indica la distancia que hay de una cavidad a otra, mientras que con la preposición en se hace referencia a la situación de transito. Se apuntó con anterioridad el incremento de casos de la UFS y su hegemonía, este hecho nos permite realizar un acercamiento a los verbos que aparecen junto al fraseologismo. El verbo correr aparece en la mayoría de los casos documentados en el CORDE, ya que supone 45 casos de los 100 que se dan en este siglo. La combinación con este verbo se manifiesta en los diccionarios fraseológicos, no obstante, otro verbo que según las obras lexicográficas suele aparecer con la UFS es andar. Este solo aparece en dos ocurrencias de la UF, hecho que llama la atención al no corroborarse los datos aportados por las obras lexicográficas y en su lugar destacan verbos como circular, repetirse y volar.

\subsection{De la diacronía a la sincronía: siglos XX y XXI}

Los datos del siglo XX se extrajeron del corpus diacrónico de referencia y del sincrónico de referencia (CORDE y CREA), pues el primero de ellos da cuenta de prácticamente la totalidad de los siglos y las décadas que faltan para completar el siglo se obtuvieron del CREA. Las ocurrencias extraídas de estos dos corpus son más del doble presentadas en el siglo anterior, con un total de 241 casos. Por ello, es conveniente exponer qué tipo de estructuras nos vamos a encontrar en los más de doscientos casos obtenidos del CORDE y CREA:

\begin{tabular}{|c|c|}
\hline Tipo de estructura & Casos \\
\hline Unidad fraseológica & 151 \\
\hline \multirow{4}{*}{ Variantes (32) } & boca a boca (13) \\
\cline { 2 - 2 } & el boca a boca (9) \\
\cline { 2 - 2 } & un boca a boca (2) \\
\cline { 2 - 2 } & de boca a boca (2) \\
\cline { 2 - 2 } & del boca a boca $(6)$ \\
\hline \multirow{4}{*}{ Variaciones (35) } & boca a boca (24) \\
\cline { 2 - 2 } & el boca a boca (14) \\
\cline { 2 - 2 } & un boca a boca (3) \\
\cline { 2 - 2 } & de boca a boca (4) \\
\hline \multirow{4}{*}{ Combinación libre de palabras (13) } & del boca a boca $(\varnothing)$ \\
\cline { 2 - 2 } & boca a boca $(5)$ \\
\hline \multirow{2}{*}{$\mathbf{2 4 1}$} & de boca en boca $(5)$ \\
\hline
\end{tabular}

Figura 10: Ocurrencias del siglo XX. 
La prolijidad del siglo XX se manifiesta desde un principio, pues el primer caso data del 1902 y es una combinación libre (boca a boca). Tras esta ocurrencia se sucederán más de 15 casos de la UF en seis años, cuyos verbos son de movimiento y predomina correr:

(13) Corrieron alli de boca en boca noticias referentes al duelo del día anterior.

A finales de la primera década del siglo hallamos cuatro variaciones de la variante diacrónica boca á boca que aparecen con el mismo valor y verbo que los casos de boca a boca (XIII). En estas aparece el verbo hablar y la variación posee el significado 'relación o transmisión oral directa', variación formada y consolidada mediante la complementación de dos metonimias y una metáfora (ver figura 7). El predominio de la UF es incuestionable, esta unidad se ha fijado y muestra de ello son los numerosos casos que presenta frente a las otras formas. A finales de los treinta y principios de los cuarenta aparecen dos variaciones de la variante de boca a boca cuyo significado figurado es 'contagiar' y el procedimiento figurativo que se produce en la creación de esta variación es la metonimia (ver figura 9). Desde el 1941 hasta el 1961 los casos registrados pertenecen únicamente a la LS de boca en boca, son 20 años en los que no hay productividad de variaciones y variantes, tan solo hallamos la aparición de tres combinaciones libres (dos con la estructura de boca a boca y una de de boca en boca). Los casos del 1951 presentan la estructura de boca a boca y el significado literal 'transmisión de un líquido u objeto de una cavidad bucal a otra'.

En 1962 aparece la variación de la variante boca a boca cuyo significado figurado es 'relación o transmisión oral directa', sin embargo, es digno de mayor resalte la aparición de una nueva variación de dicha variante con la estructura el boca a boca:

(14) Para mí que le estuvo haciendo el boca a boca, tú me dirás.

\section{(15) Estuvo haciendo el boca a boca.}

En (14) y (15) aparece una variación de la variante boca a boca formada mediante la variación estructural morfosintáctica por nominalización, y el significado que presenta es '[respiración] provocada en una persona accidentada, consistente en aplicar la boca a la de esa persona para insuflarle aire con un ritmo determinado'. Esta variación posee un homónimo literal que es 'pasar algo de una cavidad bucal a otra' y en cierto modo es el significado que tiene la variación, con la diferencia de que se pasa aire en unas determinadas circunstancias.

Entre 1966 y 1983 las estructuras que coexisten son la UFS y la variación de la variante boca a boca con el significado '[respiración] provocada en una persona accidentada, consistente en aplicar la boca a la de esa persona para insuflarle aire con un ritmo determinado'. Esta variación además de presentar la forma nominalizada el boca a boca, aparece con la misma estructura que su variante boca a boca. La variante boca a boca hasta este momento es la más productiva en este siglo, pues ha dado lugar a la variación (el) boca a boca y también en 1983 aparecerá otra variación, se trata del siguiente caso:

(16) Aquel Welch me envía un boca a boca; esto es, un saludo verbal, no teman. 
En el caso (16) hallamos una variación estructural morfosintáctica por nominalización al aparecer el artículo indefinido un. El procedimiento figurativo que interviene en la formación de esta variación es la metonimia EL TODO POR LA PARTE, pues se asocian dos entidades conceptuales contiguas que pertenecen al mismo dominio y en él hallamos un PR y una ZA:

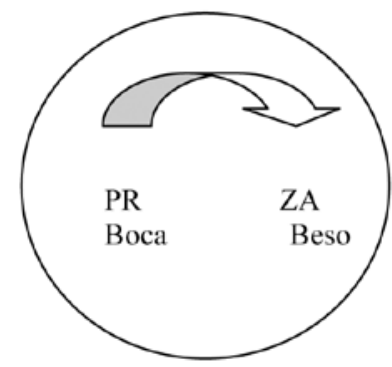

Figura 11: Procedimiento metonímico de un boca a boca con el significado de 'saludo'.

Nos hallamos ante una metonimia conceptual en la que el PR hace referencia de manera implícita a la zona activa (beso), de este modo enviar un boca a boca equivale a "enviar un beso', y por lo tanto, es un tipo de saludo.

En el 1985 aparece de nuevo la variante de boca a boca, sin embargo, dicha variante no tendrá prácticamente peso, ya que se produce la coexistencia de la UF con la variación el boca a boca de la variante boca a boca y se producirá una novedad, la aparición de dos variantes nuevas:

(17) Al menos una vez al año, la Golden Line anunciaba drásticos cambios en la empresa: ascensos, descensos, promociones, nombramientos y despidos. La noticia recorría vertiginosamente la agencia en un boca a boca extraoficial, y durante algunas semanas el personal se esforzaba más que nunca en hacer méritos.

(18) Al margen de los comunicados, los socios de Cartera Central propalan por el método del boca a boca algunos asuntos de mayor gravedad: Mario Conde no está interesado en la gestión.

El (17) es una variante gramatical al sustituirse $e n>a$ y también se lleva a cabo otro procedimiento, una variación estructural léxico-cuantitativa por reducción al desaparecer la preposición de y otra por incremento de la estructura mediante el artículo un que nominaliza la estructura (variación estructural morfosintáctica por nominalización). El caso (18) representa una nueva variante fruto de de boca a boca, se trata de del boca a boca y de esta cabe destacar que en el ejemplo se presenta como un método de comunicación y divulgación de información. Por otro lado, nos hallamos ante una variante de la UF, ya que posee el mismo significado que esta y en concreto, nos hallamos ante una variante gramatical al sustituirse $e n>a$. Otro procedimiento que se lleva a cabo y altera la estructura pero no el significado de esta es la variación estructural léxico-cuantitativa por incremento, pues entre la preposición de y el núcleo somático aparece el artículo definido el. 
Los últimos años del siglo XX presentan un abanico de estructuras ya sea por las diversas variaciones, las variantes (el) boca a boca y de boca a boca, o de boca en boca como UF. De los últimos casos que manifiesta este siglo se debe destacar un rasgo que subyace a las variantes del boca a boca y boca a boca, se trata de un contexto de uso que solo presentan estas dos variantes y que se anticipó en el análisis de la ocurrencia (18):

(19) Por otro lado, cuatro ministros daban mitines en cines y locales cerrados siguiendo con la campaña del boca a boca.

En este caso el fraseologismo hace referencia a realizar propaganda o publicidad, por lo que en este contexto de uso el fraseologismo se muestra como un sistema de promoción. Este contexto de uso se puede considerar integrado en la acepción de de boca en boca y de boca a boca [3], no obstante, se debe tener en cuenta que no es lo mismo saber de un rumor o noticia mediante la transmisión oral en conversaciones que realizar la promoción de un producto o programa mediante un sistema llamado "boca a boca". Casos como el (18) y el (19) se producen a finales del siglo XX y el hecho de que se revise este significado y se contemple como una acepción distinta o incluida en la proporcionada por el DFDEA depende de la trascendencia que este uso presente en el siglo XXI. El siglo XX presenta numerosas variaciones, la variante (el) boca a boca y la unidad fraseológica, panorama que se prolonga hasta el siglo XXI, tal y como se expondrá a continuación.

El hecho de que en los primeros años del siglo XXI ya haya casos deja entrever que no hay ruptura entre un siglo y otro, sino que se continúa con los casos de el boca a boca y del boca a boca que clausuraron el siglo anterior. Un dato a tener en cuenta es que en el siglo XXI hay casos de (el) boca a boca en un contexto de uso determinado que presentan esta estructura como un sistema de propaganda y realización de publicidad.

Las aportaciones que se pueden realizar en torno al siglo XXI son conjeturas que se constatarán o refutarán. La primera conjetura tiene que ver con el análisis cuantitativo, se ha observado que a partir del siglo XIX el número de casos (tanto de la UFS como de sus variantes y variaciones) ha incrementado cada siglo de manera considerable, y a pesar de tener 32 casos, estos se han registrado en un periodo de 14 años (los años que ya han transcurrido del siglo XXI). No obstante, si tomamos la primera década observamos que son 30 los casos que se producen, por lo que si se mantiene este número de ocurrencias por década la UF consolidada en el siglo XX podrá incluso presentar y fijar nuevas variantes o variaciones que en el siglo XX no se han consolidado, como es el caso de un boca a boca.

La segunda conjetura se expuso al final del análisis del siglo XX y es el hecho de que si se sigue utilizando del boca a boca y el boca a boca como sistema publicitario los diccionarios deberán tener en cuenta este contexto de uso y barajar la posibilidad de incluirlo en la entrada de de boca a boca o de boca a boca; o bien contemplarlo como un contexto de uso.

\subsection{Verbos y evidencialidad}

La locución somática analizada en los apartados anteriores presenta el significado actual 'divulgándose en conversaciones o comentarios, o en transmisión oral' y de este se desprende indicadores de la fuente y modo de adquisición de la información. A través del 
verbo que acompaña a la locución se puede observar el aspecto evidencial que aporta, no obstante, en primer lugar se debe indagar en el concepto de evidencialdad que propone Aikhenvald (2011):

Is a grammatical category with source of information as its primary meaning -whether the speaker saw the event happen (known as visual evidential), or hear it but didn't see it (non-visual evidential), or made an inference based on general knowledge or visual traces (assumed evidential and inferential evidential respectively), or was told about it (known as reported, second hand, or hearsay evidential) (Aikhenvald, 2011: 602).

Esta autora, además de distinguir diferentes tipos de información en función de la obtención de la misma, realiza diferentes clasificaciones de la evidencialidad en categorías gramaticales como deícticos, sustantivos y verbos (Aikhenvald, 2004; 2011). De la aportación de Aikhenvald, nos interesa especialmente la clasificación de los diferentes verbos, ya que "different evidential specifications come from (A) verb of speech, (B) verbs of perception, and, less frequently, (C) verbs of other semantic group" (Aikhenvald, 2011: 604). Asimismo, también se debe tener en cuenta la clasificación que realiza esta autora en función de cómo se adquiere la información: I. Visual, II. No visual, III. Inferencia, IV. Supuestos, V. Rumor, y VI. Citas (Aikhenvald, 2004: 63-64).

La locución somática, tal y como se ha mostrado a lo largo del análisis de su fraseologización, puede aparecer tanto con verbo como sin él. Con la finalidad de indagar en la evidencialidad de las diferentes variantes y variaciones, se realizará una aproximación a los verbos que aparecen junto a las construcciones fijas de palabras. De los datos obtenidos en los corpus se extrae el predomino de verbos de movimiento como correr, ir o saltar. Frente a dicha hegemonía hallamos verbos de lengua que apenas aparecen en 15 ocasiones, de las cuales 10 pertenecen a boca a boca. Esto se debe al significado de la variación ('relación o transmisión oral directa') ya que se hace referencia a la fuente primaria de la información, así como al modo en que ha sido adquirida (mediante la audición de la información). La obtención de la información se realiza de manera presencial, y muestra de ellos se da a través de verbos como hablar o comunicar. Además, si tenemos en cuenta la clasificación llevada a cabo por Aikhenvald (2004: 63), la evidencialidad que se muestra en boca a boca pertenece al segundo grupo que distingue: información no visual. Llama poderosamente la atención que a diferencia de boca a boca, en los casos de de boca a boca y de boca en boca no se han obtenido ocurrencias con el verbo hablar, y la mayoría de los casos presentan un verbo de movimiento como saltar, ir o volar.

Inherente a la definición de de boca en boca es la intervención de la audición, y si en el párrafo anterior se ha planteado los verbos de lengua mediante los cuales se presentaba la situación $X$ dice/habla $A$, a continuación se presentará la situación $X$ oye/ve $A$. De este modo, los casos correspondientes a los verbos de percepción (segundo tipo de verbo en la clasificación de Ankhenvald) se reducen a oir. No es de extrañar que aparezca dicho verbo, pues la locución hace referencia a la transmisión oral y esta solo se percibe mediante la audición. Por ello, nos encontramos ante el segundo tipo de obtención de información (al igual que ocurría con boca a boca), debido a que esta se obtiene a través del sentido auditivo. Sin embargo, se debe destacar que no aparecen verbos semejantes a oir como escuchar y tan solo se produce una ocurrencia con este verbo a lo largo del proceso de fraseologización. 
Por último, se debe destacar la escasez de verbos que conlleven evidencialidad, ya que en primer lugar, numeras ocurrencias se presentan sin verbo y en el caso de que la UF o sus variantes aparezcan junto a un verbo, en la mayoría de estas se trata de verbos de movimiento. Así pues, se debe destacar la aparición relativamente abundante de verbos de habla en los casos de boca a boca en contraposición con las combinaciones de boca a boca y de boca en boca.

\section{Conclusiones}

La intersección entre la fraseología y la lingüística cognitiva ha dado como resultado el estudio de la locución somática de boca en boca desde las perspectivas diacrónica y sincrónica. Se debe tener en cuenta la aportación del cognitivismo no solo en el estudio de la fijación y consolidación del fraseologismo, sino el papel que los mecanismos como la metáfora y la metonimia han desempeñado en el análisis semántico de de boca en boca. A través de la complementación de metáforas y metonimias se ha demostrado que la corporeidad se presenta como fundamental para expresar y entender el mundo que nos rodea. Cuenta de ello se ha dado en el apartado correspondiente al análisis, pues los diferentes mecanismos figurativos muestran la implicación de las funciones y propiedades del órgano boca en la creación de nuevos significados.

El análisis diacrónico hacia las raíces de la LS de boca en boca pone de manifiesto la importancia de la diacronía para entender la sincronía, pues se ha podido observar su productividad mediante las numerosas variantes y variaciones que se han creado en torno a esta unidad fraseológica. La mayoría de las variantes se han consolidado y hoy en día aparecen en las obras lexicográficas, no obstante, se debe destacar del boca a boca y (el) boca a boca. Estas combinaciones fijas de palabras aparecen a finales del siglo XX y desde su aparición se observa la tendencia ascendente del número de ocurrencias en un contexto determinado en el que el significado se concreta al contemplarse como un método o sistema de divulgación con fines comerciales y publicitarios. Debido al número de casos de estos fraseologismos, se prevé que en las próximas obras lexicográficas se tengan en cuenta y por lo tanto, estas construcciones sean incluidas como un contexto de uso, o bien se cree una entrada lexicográfica nueva.

Debido a la profundidad histórica que presenta la unidad fraseológica y a su prolijidad, se ha podido llevar a cabo una aproximación a los verbos que aparecen junto a estas construcciones. En concreto, se ha indagado en la evidencialdiad que el componente verbal puede aportar y es digno de reseñar el contraste que se observa entre la variación boca a boca (siglo XIII) y las demás variantes, ya que la primera se combina con verbos de habla, frente al resto de construcciones que aparecen con verbos de movimiento.

De la interdisciplinaridad de la fraseología subyace un amplio abanico vías y perspectivas de análisis desde las cuales se puede abordar una unidad fraseológica. En el presente trabajo se optó por la adopción de las perspectivas diacrónica y sincrónica, con la finalidad de contribuir a los estudios diacrónicos de los fraseologismos. Asimismo, se ha mostrado el grado de convencionalización que tanto de boca en boca como las variantes y variaciones presentan, ya que los hablantes las utilizan sin percibir los mecanismos cognitivos que las vertebran. Del estudio llevado a cabo se desprende la rentabilidad de la complementación de la fraseología y la cognición, así pues, debido a los resultados obtenidos se indagará en 
otros fraseologismos con el núcleo somático boca adoptando la metodología de este artículo. Así pues, en futuras investigaciones se abordará el estudio de la locución somática punto en boca y su posible vinculación al ámbito costurero u ortográfico, incógnita que se despejará a través de las metáforas y metonimias.

\section{Referencias bibliográficas}

Aikhenvald, A. Y. (2004): Evidentiality, Oxford/New York, Oxford University Press.

Aikhenvald, A. Y. (2011): "The grammaticalization of evidentiality". En Heine, H. y H. Narrog, págs. 602-610.

Adam Stepién, M. (2007): "Metáfora y metonimia conceptual en la fraseología de cinco partes del cuerpo humano en español y polaco", Anuario de Estudios Filológicos, $\mathrm{n}^{\mathrm{o}}$ 30, págs. 391-409: http://dehesa.unex.es:8080/xmlui/bitstream/handle/10662/913/0210-8178_30_391.pdf?sequence=4 (05-05-2014).

Álvarez de la Granja, M. (2008): Lenguaje figurado y motivación: una perspectiva desde la fraseología, Frankfurt, Peter Lang.

Carneado, Z y A. M. Tristá (1980): Estudios de fraseología, La Habana, Instituto de Literatura y Lingüística.

Casares, J. (1992[1950]): Introducción a la lexicografía moderna, Madrid, Consejo Superior de Investigaciones Científicas.

Chomsky, N. (1957): Syntactic structures, La Haya, Mouton de Gruyter.

Coromines, J. y J. A. Pascual (1980-1991): Diccionario crítico etimológico de la lengua castellana, Madrid, Gredos.

Corpas Pastor, G. (1997): Manual de fraseología española, Madrid, Gredos.

Croft, W. y D. A. Cruse (2004): Cognitive Linguistics, Cambridge, Cambridge University Press.

Cuenca, J. M. y J. Hilferty (2013): Introducción a la lingüistica cognitiva, Barcelona, Ariel Lingüística.

Díaz-Vera, J. E. (ed.) (2015): Metaphor and metonymy across time and cultures: Perspectives on the sociohistorical linguistics of figurative language, Berlin/Munich/Boston, Walter de Gruyter GmbH.

Echenique Elizondo, M. T. y M. J. Martínez Alcalde (2011): Diacronía y gramática histórica de la lengua española, Valencia, Tirant Humanidades.

Fauconnier, G. (1994): Mental spaces: aspects of meaning construction in natural language, Cambridge, Cambridge University Press.

Fillmore, C. (1985): "Frame and the semantics of understanding", Quaderni di Semantica, 6, págs. 222-254.

García-Page, M. (2008): Introducción a la fraseología española: estudio de las locuciones, Barcelona, Anthropos.

Geeraerts, D. (ed.) (2006): Cognitive Linguistics: Basic Readings, Berlin/New York, Mouton de Gruyter.

Geeraerts, D. (2010): Theories of Lexical Semantics, Oxford, Oxford University Press.

Heine, B. y T. Kuteva (2005): Language Contact and Grammatical Change, Cambridge, Cambridge University Press.

Heine, B. y H. Narrog (2011): The Oxford Handbook of Grammaticalization, Cambridge, Cambridge University Press. 
Hopper, P. J. y E. C. Traugott (2003): Grammaticalization, Cambridge, Cambridge University Press.

Ibarretxe-Antuñano, I. y J. Valenzuela (dirs.) (2012): Lingüística Cognitiva, Barcelona, Anthropos Editorial.

Johnson, M. (1987): The body in the mind. The bodily basic of meaning, imagination and reason, Chicago, University of Chicago Press.

Lakoff, G. y M. Johnson (1980): Metaphors we live by, Chicago, The University of Chicago Press.

Langacker, R. W. (1999): Grammar and conceptualization, Berlin/New York, Mouton de Gruyter.

Langacker, R. W. (2009): Investigations in Cognitive Grammar, Berlin/New York, Mouton de Gruyter.

López, C. (2002): Aspectos de fraseología contrastiva (alemán-español) en el sistema y en el texto, Frankfurt, Peter Lang.

Martí Contreras, J. (2004): "Introducción a proyectos fraseológicos en el siglo XVIII”, Res Diachronicae, 3, págs. 67-71: https://resdiachronicae.files.wordpress.com/2013/12/volumen-3-08_67_72_martinez_contreras_jorge.pdf (14-07.2015).

Martínez López, J. A. y A. Myre Jorgensen (2009): Diccionario de expresiones y locuciones del español, Madrid, Ediciones de la Torre.

Mena Martínez, F. y G. Corpas Pastor (2003): “Aproximación a la variabilidad fraseológica de las lenguas alemana, inglesa y española”, Estudios de Lingüística de la Universidad de Alicante, 17, págs. 181-202.

Moliner, M. (2007): Diccionario de uso del español, Madrid, Gredos.

Montoro del Arco, E. T. (2006): Teoría fraseológica de las locuciones particulares: las locuciones prepositivas, conjuntivas y marcadoras en español, Frankfurt, Peter Lang.

Olza Moreno, I. (2011a): Corporalidad y lenguaje: la fraseología somática metalingüistica del español, Frankfurt, Peter Lang.

Olza Moreno, I. (2011b): “Aspectos sobre la relación de idiomaticidad, metáfora y metonimia”. En Santibáñez, C. y J. Osorio, págs. 167-216.

Peirsman, Y. y D. Geeraerts (2006): "Metonymy as a prototypical category", Cognitive Linguistics, 17 (3), págs. 269-316.

Pérez-Salazar Resano, C. (2007): “Unidades fraseológicas y diacronía. Sobre las fórmulas negativas de ninguna manera y en absoluto", Estudios Humanísticos. Filología, 29, págs. 253-281: file://C:/Users/Alicia/Downloads/Dialnet-UnidadesFraseologicasYDiacronia-2339406\%20(2).pdf (12-07-2015).

Ruiz Gurillo. L. (1997): Aspectos de fraseología teórica española, Valencia, Universidad, Anejo XXIV de Cuadernos de Filología.

Ruiz Gurillo, L. (1998): La fraseología del español coloquial, Barcelona, Ariel.

Ruiz Gurillo, L. (2000): "Las metáforas de un día en los medios de comunicación españoles", Estudios de Lingüistica de la Universidad de Alicante, 14, págs. 199-215.

Ruiz Gurillo, L. (2001): "La fraseología como cognición: vías de análisis”, Lingüistica Española Actual, XXIII, págs. 107-132.

Santibáñez, C. y J. Osorio (2011): Recorridos de la metáfora: cuerpo, espacio y diálogo, Concepción (Chile), Cosmigonon Editorial.

Seco, M. (dir.) (2004): Diccionario fraseológico documentado del español actual: locuciones y modismos españoles, Madrid, Aguilar lexicografía. 
Seco, M., O. Andrés y G. Ramos (2011): Diccionario del español actual, Madrid, Aguilar lexicografía.

Traugott, E. C. y R. B. Dasher (2002): Regularity in semantic change, Cambridge, Cambridge University Press.

Varela, F. y H. Kubath (1996): Diccionario fraseológico del español moderno, Madrid, Gredos.

Real Academia Española: Banco de datos CORDE: Corpus diacrónico del español. Disponible en http://www.rae.es (04/06/2014).

Real Academia Española: Banco de datos CREA: Corpus de referencia del español actual. Disponible en http://www.rae.es (04/06/2014).

Real Academia Española: Banco de datos CORPES XXI: Corpus del español del siglo XXI. Disponible en http://www.rae.es (04/06/2014).

Zuluaga, A. (1980): Introducción al estudio de las expresiones fijas, Berne, Peter Lang. 